10. Jenner, F. A., and Pollitt, R. J.: Large quantities of 2-acetamido-1-(beta-L-aspartamido)-1,2-dideoxyglucose in the urine of mentally retarded siblings. Biochem. J., 103: $48(1967)$

11. Kaback, M. M., Zeiger, R. S., Reynolds, L. W., and Sonneborn, M.: Approaches to the control and prevention of Tay-Sachs disease. In: A. G. Steinberg and A. G. Bearn: Progress in Medical Genetics, Vol. X, p. 103 (Grune and Stratton, New York, 1974).

12. Lie, S.: Personal communication, 1975

13. Lowry, A., Rosebrough, N. J., Farr, A. L., and Randall, R. J.: Protein measurement with Folin phenol reagent. J. Biol. Chem., 190: 265 (1951).

14. Makino, M., Kojima, T., and Yamashina, I.: Enzymatic cleavage of glycopeptides. Biochem. Biophys. Res. Commun., 24: 961 (1966).

15. Masson, P. Lundblad, A., and Autio, S.: Mannosidosis: Detection of the disease and of heterozygotes using serum and leukocytes. Biochem. Biophys. Res. Commun., 56: 296 (1974).

16. Nadler, H. L.: Acid phosphatase deficiency. In: H. G. Hers and F. Van Hoof: Lysosomes and Storage Diseases (Academic Press, New York, 1973).

17. Palo, J., and Mattson, K.: Chromatographic isolation of 2-acetamido-l-(beta'-Laspartamido)-1,2-dideoxyglucose from urine. J. Chromatogr., 50: 534 (1970).
18. Palo, J., Pollitt, R. J., Pretty, K. M., and Savolainen, H.: Glycoasparagine metabolites in patients with aspartylglucosaminuria: Comparison between English and Finnish patients with special reference to storage materials. Clin. Chim. Acta, 47: 69 (1975)

19. Palo, J.. Riekkinen, P.. Arstila, A. U., Autio, S., and Kivimäki, T.: Aspartylglucosaminuria. II. Biochemical studies on brain, liver, kidney and spleen. Acta Neuropathol. (Berlin), 20:217 (1972).

20. Pollitt, R. J and Jenner, F. A.: Enzymatic cleavage of 2-acetamido-1-(beta'L-aspartamido)-1,2-dideoxy-beta-D-glucose by human plasma and seminal fluid: Failure to detect the heterozygous state for aspartylglucosaminuria. Clin Chim. Acta, 25: 413 (1969).

21. Pollitt, R. J., Jenner, F. A., and Merskey, H.: Aspartylglucosaminuria: An inborn error of metabolism associated with mental defect. Lancet, ii: 253 (1968).

22. This study was supported by grants from Sigrid Jusélius Foundation and the National Research Council for Medical Sciences, Finland.

23. Requests for reprints should be addressed to: P. Aula, M.D., Children`s Hospital, 00290 Helsinki 29 (Finland).

24. Accepted for publication January 14, 1976
$\beta$-Galactosidase heterozygote Hurler syndrome
$\alpha$-L-iduronidase leukocytes

\title{
Hurler Syndrome: $\alpha$-L-Iduronidase Activity in Leukocytes as a Method for Heterozygote Detection
}

\author{
REBECCA S. WAPPNER ${ }^{29 \prime}$ AND IRA K. BRANDT
}

Departments of Pediatrics and Medical Genetics, Indiana University School of Medicine, Indianapolis, Indiana, USA

\section{Extract}

$\alpha$-L-Iduronidase activity and $\beta$-galactosidase activity were determined in mixed leukocyte preparations in $\mathbf{1 0}$ families in which the Hurler syndrome had occurred. Affected patients, heterozygotes, and normal subjects were clearly distinguished by $\alpha$-L-iduronidase activity alone. Patients had 0-3\%, obligate heterozygotes 19-60\%, and normal subjects $83-121 \%$ of the mean normal activity. There was no overlap between heterozygotes and normal subjects. Although the mean $\alpha$-L-iduronidase to $\beta$-galactosidase ratio was significantly lowered in heterozygotes when compared with that of normal subjects, appreciable overlap was noted between the two groups.

\section{Speculation}

Carriers and affected individuals for Hurler syndrome can be reliably detected using mixed leukocyte preparations for the determination of $\alpha$-L-iduronidase activity. As technology improves enzyme assays will become reliable enough for determination of heterozygotes for an increasing number of disorders, thus enabling more thorough and accurate genetic counseling.

The Hurler and Scheie syndromes (mucopolysaccharidosis $\mathbf{I H}$ and IS, respectively) are autosomal-recessive disorders characterized by deficient activity of the lysosomal enzyme (ec. 3.2.1.76) $\alpha$-L-iduronidase $(2,9,14,16)$. This enzymatic defect results in generalized lysosomal accumulation and excessive urinary excretion of partially degraded mucopolysaccharides containing iduronic acid residucs: heparan sulfate and dermatan sulfate $(6,8)$.

Using phenyl- $\alpha$-L-iduronide as a substrate, $\alpha$-L-iduronidase activity has been demonstrated to be reduced in leukocytes, serum, and cultured skin fibroblasts from obligate heterozygotes for the Hurler and Scheie syndromes $(9,14)$. Hall and Neufeld (9) demonstrated that the $\alpha$-L-iduronidase activity of Hurler heterozygous cultured skin fibroblasts varied from 20 to $95 \%$ of normal, with a mean value of $46 \%$. This range overlapped that of material obtained from normal control subjects. Liem and Hooghwinkel (14) demonstrated $\alpha$-L-iduronidase activity of 30 and $53 \%$ of normal control subjects in mixed leukocyte preparations from two Hurler obligate heterozygotes. Singh et al. (17) have reported $\alpha$-L-iduronidase activity in serum of one Hurler obligate heterozygote and one Scheie obligate heterozygote of 12 and $19 \%$ of normal, respectively.

Although it is known that other lysosomal enzymes differ in specific activity among different leukocyte cell types $(3,12)$ and that factors resulting in a change from the normal differential may affect the reliability of carrier detection when mixed leukocyte preparations are used, no data have been published concerning the relative distribution of $\alpha$-L-iduronidase among various leukocyte cell types.

We report a modified assay for $\alpha$-L-iduronidase activity which employs mixed leukocyte preparations. The assay was used for controlled studies of families in which the Hurler syndrome has occurred and appears to be sufficiently accurate and precise to enable the detection of heterozygosity with greater than $95 \%$ confidence. 


\section{MATERIAL AND METHODS}

Ten patients with the Hurler syndrome and their families have been followed at the Indiana University Hospitals over the past 10 years. Two patients who expired before the availability of enzyme diagnosis had the clinical manifestations of classic Hurler syndrome and documented mucopolysacchariduria, mainly of heparan sulfate and dermatan sulfate.

Blood samples $(10-20 \mathrm{ml})$ were drawn into heparinized plastic syringes. Plasmagel (20) was added (4:1, whole blood-Plasmagel), the mixture inverted 10 times, and the syringes allowed to stand 30 min for sedimentation of the erythrocytes. The plasma-leukocyte suspension was aspirated into $50-\mathrm{ml}$ plastic conical centrifuge tubes and centrifuged at $150 \times g$ for $20 \mathrm{~min}$ at $4^{\circ}$. The cells were washed once with isotonic saline, the erythrocytes lysed with osmotic shock (distilled water for $45 \mathrm{sec}$ ), and the cells further washed three times with $0.05 \mathrm{M} \mathrm{NaCl}$. The cells were then suspended in $1 \mathrm{ml} 0.15 \mathrm{M} \mathrm{NaCl} / 20 \mathrm{ml}$ original whole-blood volume, quick-frozen and thawed three times, and the suspension centrifuged at $10,000 \times g$ for $15 \mathrm{~min}$ at $4^{\circ}$. The supernatant was removed and, if not used immediately, stored at $-70^{\circ}$.

Protein was measured using a modification of the Lowry method (15). The supernatants contained between 1.2 and $3.0 \mathrm{mg}$ protein $/ \mathrm{ml}$.

$\alpha$-L-Iduronidase activity was determined as previously described by Hall and Neufeld (9) with modifications. Incubations were carried out in $1-\mathrm{ml}$ glass conical centrifuge tubes $(21)$. Incubation mixtures contained $10 \mu 10.01 \mathrm{M}$ phenyl- $\alpha$-L-iduronide (22); $20 \mu \mathrm{l}$ $0.4 \mathrm{M}$ sodium formate buffer, $\mathrm{pH} 3.5$, containing $0.15 \mathrm{M} \mathrm{NaCl}$ and $0.10 \% \mathrm{NaN}_{3}$; supernatant $(50-100 \mu \mathrm{g}$ protein); and sufficient $0.15 \mathrm{M} \mathrm{NaCl}$ to bring the total volume to $80 \mu \mathrm{l}$. Controls with water instead of substrate were run for each supernatant because of the high color production noted with the supernatant alone.

After $18 \mathrm{hr}$ at room temperature, $270 \mu \mathrm{l}$ freshly diluted Folin-Ciocalteau reagent (23) (1 part reagent to 2 parts water) were added. The protein precipitate was removed by centrifugation at $2,000 \times \mathrm{g}$ for $15 \mathrm{~min}$ at $4^{\circ}$. Two hundred microliters of the supernatant were carefully removed and transferred to a test tube and allowed to come to room temperature. Three hundred microliters of $12 \% \quad \mathrm{Na}_{2} \mathrm{CO}_{3}$ were added with immediate mixing and the color developed at $37^{\circ}$ for $20 \mathrm{~min}$. Absorbance was read at $660 \mathrm{~nm}$ in a Gilford spectrophotometer (24) against a substrate blank.

$\beta$-Galactosidase activity was measured as previously described by Hall and Neufeld (9). Incubation mixtures contained $50 \mu 10.04$ M $p$-nitrophenyl- $\beta$-galactopyranoside (23); $100 \mu 10.5 \mathrm{M}$ sodium acetate buffer, $\mathrm{pH} 5.0$; supernatant $(40-100 \mu \mathrm{g}$ protein) and distilled water to a total volume of $500 \mu \mathrm{l}$. After $1 \mathrm{~h}$. at $37^{\circ}$ the tubes were immediately iced and $1 \mathrm{ml} 0.05 \mathrm{M} \mathrm{NaOH}$ was added. The mixture was centrifuged at $1,000 \times g$ for $3 \mathrm{~min}$ and the absorbance read at $400 \mathrm{~nm}$ in a Gilford spectrophotometer (24) against a substrate blank.

In a supplemental study leukocyte counts and differentials were done on simultaneously obtained whole blood samples using EDTA as an anticoagulant. Leukocyte counts were done using a Coulter counter, model F (25), and differentials were done on peripheral blood smears stained with a Hema-Tek slide stainer (26).

\section{RESULTS}

The enzyme preparations were found to be stable for $\alpha$-Liduronidase activity for at least 4 months when stored at $-70^{\circ}$. Although age-matched controls were not employed, there was no noted variation in activity with age (6 months to 70 years). There was no statistically significant difference between male and female obligate heterozygotes $(P>0.9)$. Female obligate heterozygotes taking oral contraceptives showed no evidence of change in $\alpha$-L-iduronidase activity; however, the group was too small $(n=4)$ for any statistical significance.

The results of the enzyme assays from the initial study are shown in Figure 1, and summarized in Table I. Normal subjects, patients, and heterozygotes can be clearly distinguished by $\alpha$-L-iduronidase activity. Patients show $0-3 \%$, obligate heterozygotes $19-60 \%$, and normal subjects $83-121 \%$ of the mean normal activity.

Three individuals among the siblings and other relatives had a specific activity between the ranges of normal subjects and obligate heterozygotes. One sibling and one relative had values well within the +2.5 SD limit for the obligate heterozygotes and well outside of the - 2.5 SD limit of the control group; thus they were designated heterozygotes. The other relative, whose activity was between the $2.5 \mathrm{SD}$ limits for both groups, was considered to be a heterozygote for two reasons. First, her level of specific activity was well below the lowest normal in either the initial or supplemental study. And, second, family studies revealed her husband to have normal activity whereas her two daughters had levels in the obligate heterozygote range.

A supplemental study of normal persons was carried out to determine whether minor spontaneous normal variations in the relative concentrations of the different types of leukocytes would affect the results of the enzyme assays. Of the 15 persons evaluated, 8 were also in the initial study. All individuals had leukocyte counts and differentials within the normal range. The results were as follows: group $A$ ( $\alpha$-L-iduronidase), mean $242 \pm 37$ SD, range 183311 , reported as nanomoles of phenol liberated per $18 \mathrm{hr}$ per mg protein; group $B$ ( $\beta$-galactosidase), mean $146 \pm 28$ SD, range 104-198, reported as nanomoles of $p$-nitrophenol liberated per hr per mg protein; group C (ratio of group A to group $B$ ), mean $1.69 \pm 0.32 \mathrm{SD}$, range 1.242 .57 . There was no statistically significant difference between the two groups of normal subjects in any of the three determinations. Although the second group of normal subjects had a wider range of specific activity, there was no overlap with that of the obligate heterozygote range. When compared with the results from obligate heterozygotes, the second group also significantly differed in $\alpha$-L-iduronidase activity $(P<0.001)$ and in the ratio of $\alpha$-Liduronidase to $\beta$-galactosidase activity $(P<0.001)$.

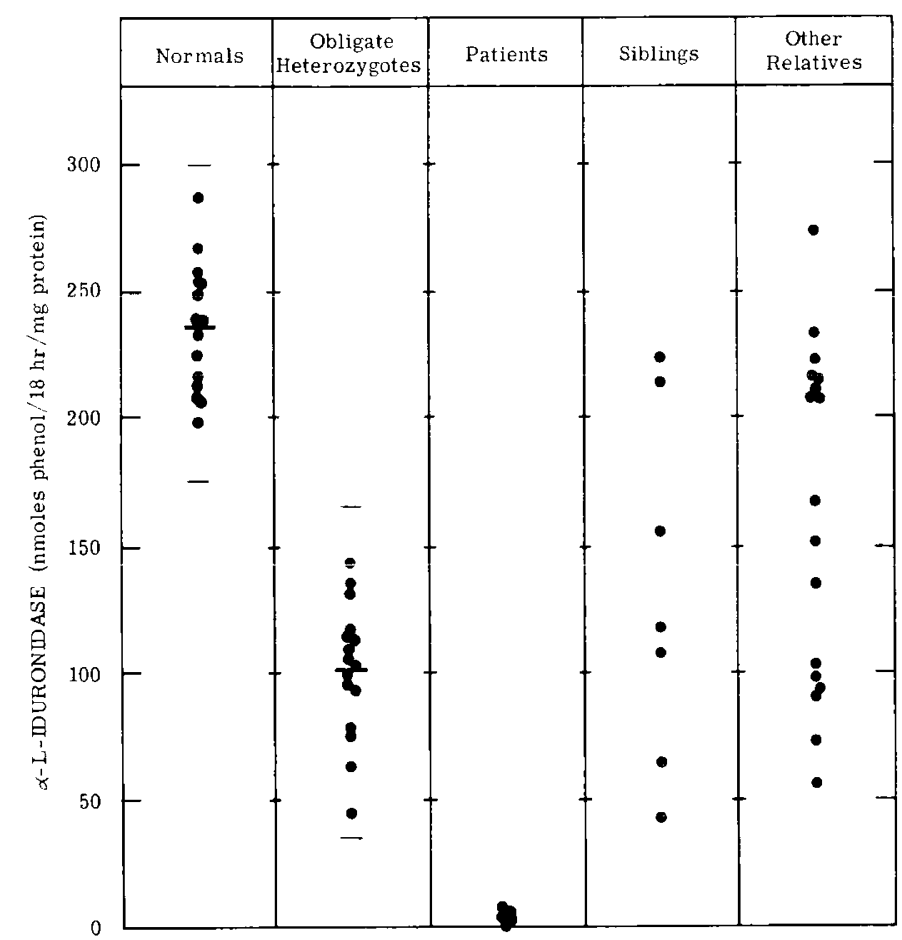

Fig. 1. $\alpha$-L-Iduronidase activity in leukocytes from children with the Hurler syndrome, their relatives, and normal unrelated persons. The horizontal bars denote the mean and $\pm 2.5 \mathrm{SD}$. (Each filled circle $(\bullet)$ represents one person, except that the single filled circle at the zero line under patients represents four patients.) 
HURLER SYNDROME

Table 1. Specific activity of $\alpha$-L-iduronidase and $\beta$-galactosidase in leukocytes from children with Hurler syndrome, their parents, and unrelated normal persons

\begin{tabular}{|c|c|c|c|c|c|}
\hline Persons & $n$ & Mean & $\mathrm{SD}$ & Range & $P$ \\
\hline \multicolumn{6}{|c|}{ Group $A: \alpha$-L-iduronidase' } \\
\hline Normals & 15 & 236 & 25 & $197-286$ & \multirow{3}{*}{$<0.001$} \\
\hline Heterozygotes & 16 & 100 & 26 & $45 \cdot 141$ & \\
\hline Patients & 8 & 2 & 2 & $0-7$ & \\
\hline \multicolumn{6}{|c|}{ Group $B: \beta$-galactosidase ${ }^{2}$} \\
\hline Normals & 14 & 137 & 33 & $103 \cdot 227$ & \multirow{3}{*}{$\begin{array}{l}>0.2 \\
>0.3\end{array}$} \\
\hline Heterozygotes & 16 & 119 & 48 & $40-215$ & \\
\hline Patients & 8 & 108 & 46 & $40-199$ & \\
\hline \multicolumn{6}{|l|}{ Group $C:$ ratio of $A / B$} \\
\hline Normals & 14 & 1.82 & 0.34 & $1.18-2.28$ & \multirow{2}{*}{$<0.001$} \\
\hline Heterozygotes & 16 & 1.00 & 0.48 & $0.34 \quad 2.33$ & \\
\hline
\end{tabular}

${ }^{3}$ Expressed as nanomoles of phenol liberated per $18 \mathrm{hr}$ per $\mathrm{mg}$ protein.

${ }^{2}$ Expressed as nanomoles of $p$-nitrophenol liberated per hr per mg protein.

\section{DISCUSSION}

The availability of a method for precise identification of heterozygotes for the Hurler syndrome will be valuable in genetic counseling for families of children affected with the disorder.

Great interest recently has been shown in assays employing leukocytes for evaluation of lysosomal enzyme abnormalities. The present study shows that both patients and heterozygotes for the Hurler syndrome can be defined in this manner.

In order to verify the results of the initial study, a supplementary study of normal subjects with known normal leukocyte counts and differentials was done. It is suggested that preliminary leukocyte counts and differentials be done on all subjects in whom mixed leukocyte preparations are to be used for lysosomal enzyme assays in order to demonstrate the absence of any extreme abnormality which might affect the results. In addition, studies should be undertaken to determine the relative specific activity of $\alpha$-L iduronidase in various leukocyte cell types when the substrate, presently in very limited supply, becomes more readily available.

Comparison of a given lysosomal enzyme to another unaffectd one has been employed as a means of improving the resolution of heterozygote identification (10). $\beta$-Galactosidase was chosen as the reference enzyme for this reason as well as the fact that it has been used previously in comparison with $\alpha$-L-iduronidase and is relatively stable in biologic samples (9). Although $\beta$-galactosidase activity has been shown to be depressed in the liver and in cultured skin fibroblasts of patients with the Hurler syndrome $(5,7,19)$, no significant lowering of the enzyme level has been noted in cultured skin fibroblasts from heterozygotes for the Hurler syndrome $(7,9)$. In the present study, leukocyte $\beta$-galactosidase activity was somewhat lower in both patients and heterozygotes than in normal subjects. Although the mean $\alpha$-L-iduronidase to $\beta$-galactosidase activity ratio was significantly lowered in heterozygotes when compared to that of normal subjects, appreciable overlap was noted between the two groups. It is suggested that subsequent similar studies employing leukocytes include lysosomal enzyme assays other than $\beta$-galactosidase.

Deficiency of activity of $\alpha$-L-iduronidase has been shown to be associated with several other forms of mucopolysaccharidosis, including the Scheie syndrome, a milder, presumably allelic form of the Hurler syndrome $(2,9,14,17)$, and the Hurler-Scheie syndrome, an intermediate "genetic compound" form $(2,4,9,11)$. In addition, deficiency of $\alpha$-L-iduronidase activity has been documented in four patients with chondroitinsulfaturia $(1,13,18)$. Although the clinical features of one case (1) were similar to those seen in the Hurler syndrome, the other three cases $(13,18)$ differed clinically from both the Hurler and Scheie syndromes. Chrondroitin sulfate does not contain $\alpha$-L-iduronic acid residues, but only $\beta$-D-glucuronic acid residues. Thus, the apparent defect in chondroitin sulfate metabolism most probably is not directly related to the deficient activity of $\alpha$-L-iduronidase. The relationship between the chondroitinsulfaturia and the deficient activity of $\alpha$-L-iduronidase remains to be defined.

\section{SUMMARY}

Homozygotes and heterozygotes for the Hurler syndrome may be clearly distinguished from normal subjects using the substrate phenyl- $\alpha$-iduronide for measurement of activity of $\alpha$-L-iduronidase in mixed leukocyte preparations. Comparison of $\alpha$ - $\mathrm{L}$-iduronidase activity and $\beta$-galactosidase activity did not strengthen the results.

\section{REFERENCES AND NOTES}

1. Babarik, A., Benson, P. F., Dean, M. F., and Muir, H.: Chondroitinsulphaturia with $\alpha$-L-iduronidase deficiency. Lancet, ii: 464 (1974).

2. Bach, G. Friedman, R., Weissman, B., and Neufeld, E. F.: The defect in the Hurler and Scheie syndromes: Deficiency of $\alpha$-L-iduronidase. Proc. Natl. Acad. Sci. U. S. A., 69: 2048 (1972)

3. Beutler, E.. and Kuhl, W.: The diagnosis of the adult type of Gaucher's disease and its carrier state by demonstration of deficiency of $\beta$-glucosidase activity in peripheral blood leukocytes. J. Lab. Clin. Med., 76: 747 (1970).

4. Danes, B. S.: In vitro confirmation of genetic compound of the Hurler and Scheie syndromes. Lancet, $i: 680$ (1974).

5. Den Tandt, W. R., and Giesberts, M. A. H.: Deficiency of lysosomal enzymes in storage diseases. Biochem. Med., 7: 441 (1973).

6. Dorfman, A., and Matalon, R.: The mucopolysaccharidoses. In: J. B. Stanbury, J. B. Wyngaarden, and D. S. Fredricksort: The Metabolic Basis of Inherited Disease, Ed. 3, p. 1218 (McGraw-Hill, New York, 1972).

7. Fluharty, A. L., Porter, M. T., Lassila, E. L., Trammel, J., Carrel, R. E., and Kihara, H.: Acid glycosidases in mucopolysaccharidoses` fibroblasts. Biochem. Med. 4: $110(1970)$

8. Fratantoni, J C Hall, C. W and Neufeld, E. F.: The Defect in Hurler's and Hunter's syndromes: Faulty degeneration of mucopolysaccharide. Proc. Natl. Acad. Sci. U. S. A., 60: 699 (1968).

9. Hall, C. W., and Neufeld, E. F.: $\alpha$-L-Iduronidase activity in cultured skin fibroblasts and amniotic fluid cells. Arch. Biochem. Biophys., 158: 817 (1973).

10. Hirschhorn, K. Nadler, H. L., Waithe, W. I., Brown, B. I., and Hirschhorn, R. Pompe's disease: Detection of heterozygotes by lymphocyte stimulation. Science, 166: 1632 (1969)

11. Kajii, T., Matsuda, I., Ohsawa, T., Katsunuma, H., Ichida, T., and Arashima, S. Hurler/Scheie genetic compound (mucopolysaccharidosis IH/IS) in Japanese brothers. S. Clin. Genet., 6: 394 (197).

12. Koster, J. F., Slee, R. G., and Hülsmann, W. C.: The use of leucocytes as an aid in the diagnosis of glycogen storage disease type II (Pompe's disease). Clin. Chim. Acta, 51: 319 (1974).

13. Leisti, J.. Rimoin, D. L., Kaback, M. M., Hollister, D. W., Den Tandt, W. Neufeld, E., Matalon, R., and Philippart, M.: Phenotypic variation in alpha-L-iduronidase deficiency. Lancet, $i: 1344$ (1975).

14. Liem, K. O., and Hooghwinkel, G. J. M.: The use of $\alpha$-L-iduronidase activity determinations in leukocytes for the detection of Hurler and Scheie syndromes. Clin. Chim. Acta, 60: 259 (1975).

15. Lowry, O. H., Rosebrough, N. J., Farr, A. L., and Randall, R. J.: Protein measurement with the Folin phenol reagent J. Biol. Chem., 193: 265 (1951).

16. Matalon, R and Dorfman, A. Hurler's syndrome, an $\alpha$-L-iduronidase deficiency. Biochem. Biophys. Res. Commun., 47: 959 (1972).

17. Singh, J., Niebes, P., and DiFerrante, N.: A Method for $\alpha$-L-iduronidase assay Fed. Eur. Biochem. Soc. Lett., 45: 248 (1974)

18. Spranger, J., Gehler, J., O'Brien, J. F., and Cantz, M.: Chondroitinsulphaturia with $\alpha$-L-iduronidase deficiency. Lancet, ii: 1082 (1974). 
19. van Hoof, F., and Hers, H. G.: The abnormalities of lysosomal enzymes in mucopolysaccharidoses. Europ. J. Biochem., 7: 34 (1968).

20. HTI Corp., Buffalo, N. Y.

21. MISCO Scientific, Berkeley, Calif.

22. Gift of Dr. Elizabeth F. Neufeld, National Institutes of Health, Bethesda. Maryland; prepared by Dr. Bernard Weissmann under Grant no NIHNIAMDD 73-2205.

23. Sigma Chemical Co., St. Louis, Mo.

24. Gilford Instrument Laboratories, Inc., Oberlin, Ohio.

25. Coulter Electronics. Inc.. Hialeah, Fla.
26. Ames Company, Division Miles Laboratories, Inc., Elkhart, Ind.

27. Informed consent was obtained for all subjects in this study.

28. This study was supported by grants from the Riley Memorial Association (Project no. 74-9) and the National Institute of Arthritis, Metabolism, and Digestive Diseases. United States Public Health Service, no. IF22 AM0338801 .

29. Requests for reprints should be addressed to: Dr. R. Wappner, The James Whitcomb Riley Hospital for Children, Rm. A-36, 1100 W. Michigan St. Indianapolis, Ind. 46202 (USA).

30. Accepted for publication January 14, 1976

\title{
The Chronically Reserpinized Rat as a Possible Animal Model for Cystic Fibrosis. IV. The Protein Composition of Pulmonary Lavage Fluid
}

\author{
FREDERICK E. THOMPSON, DAVID O. QUISSELL, CHARLES H. WILLIAMS, ${ }^{\prime 20}$ \\ AND J. R. MARTINEZ \\ Departments of Medicine, Biochemistry, and Child Health, University of Missouri and Harry S. Truman Memorial \\ Veterans Hospital, Columbia, Missouri, USA
}

\section{Extract}

Lung lavage samples obtained from patients with cystic fibrosis (CF) had significantly higher levels of total protein per $\mathrm{ml}$ lavage fluid $(0.49 v s .0 .30 \mathrm{mg} / \mathrm{ml})$. A significant increase in the absolute and relative amounts of a low molecular weight glycoprotein $(15,000 \mathrm{~mol}$ wt $)$ was noted in lavage specimens from $C F$ patients. Reserpine-treated rats also showed a significant increase in the total protein recovered in the lung lavage fluid with a $233 \%$ increase in the absolute and relative amounts of a low molecular weight glycoprotein $(15,000 \mathrm{~mol} \mathrm{wt})$. Thus, reserpine induces changes in the secretions of the lung of the rat which are similar to those observed in samples obtained from the lungs of $\mathrm{CF}$ patients.

\section{Speculation}

The administration of reserpine to rats, which has been previously shown to produce morphologic changes in various exocrine tissues and abnormaities in the composition of submaxiliary saliva similar to those reported for $\mathrm{CF}$ patients, should result in changes in the composition of other exocrine gland secretions.

Cystic fibrosis is a hereditary disorder in which there is a postulated defect in regulation of exocrine gland secretion. Typically there is a generalized accumulation of a highly viscous mucus in the ducts and surfaces of exocrine glands (4-6). Chronic bronchiolar obstruction as a result of mucous plugging and subsequent pulmonary infection are the most frequent cause of death among cystic fibrotics. The distended appearance of mucous glands of the tracheobronchial tree indicates a hypersecretory state (1).

The exact mechanism by which the genetic error is expressed remains unknown. The possible role of disturbances in the neurohumoral regulation of exocrine glands was suggested several years ago (2) and later, it was shown that chronic administration of a $\beta$-adrenergic agent (isoproterenol) to rats induced suggestive changes in the salivary glands (11). More recently, morphologic and secretory changes in the rat submaxillary gland have been induced by chronic administration of reserpine $(9,12,13)$. In this model, submaxillary saliva showed increased concentrations of protein, carbohydrate, and calcium $(10,12,13)$.

These abnormalities in the composition of submaxillary saliva from the reserpine-treated animals, together with evidence that the drug treatment also induces morphologic changes in other exocrine tissues (9), directed our interest to the protein composition of pulmonary secretions. In this investigation we have compared, therefore, the protein composition of lung lavage samples from patients with cystic fibrosis and from reserpine-treated rats. We expected to find an abnormal protein specific for cystic fibrosis, but, after a few experiments, it became evident that cystic fibrotic lavage fluid contained the same proteins found in other nonsecretory pulmonary diseases, but that they were present in different proportions. Likewise, lavage fluid from reserpine-treated rats had qualitatively the same protein electrophoretic pattern as control animals, but the quantity of one low molecular weight glycoprotein was markedly increased. Significantly, we found that a similar glycoprotein was also increased in the lavage material from cystic fibrotic patients.

\section{METHODS}

\section{RESERPINE-TREATED RATS}

This section of the study was performed on five groups of 4 adult sibling male rats for a total of 10 controls and 10 treated animals. The latter were treated daily for 7 days with intraperitoneal injections of $0.5 \mathrm{mg} / \mathrm{kg}$ reserpine $(12,13)$. On the 8 th day, both 